\title{
Cholecystocolonic fistula: facts and myths. A review of the 231 published cases
}

\author{
Renato Costi · Bruto Randone - Vincenzo Violi • \\ Olivier Scatton · Leopoldo Sarli · Olivier Soubrane · \\ Bertrand Dousset · Thierry Montariol
}

Received: 19 March 2008/Accepted: 28 April 2008/Published online: 17 December 2008

(C) Springer 2008

\begin{abstract}
Background Cholecystocolonic fistula (CCF) is the second most common cholecystoenteric fistula and is often discovered intraoperatively, resulting in a challenging situation for the surgeon, who is forced to switch to a complex procedure, often in old, unfit patients. Management of this uncommon but possible finding is still ill defined.

Methods An extensive review of 160 articles published from 1950 to 2006 concerning 231 cases of CCF was performed.

Results CCF is mostly an affliction of women in their sixth to seventh decades and is rarely diagnosed preoperatively. Chronic diarrhea is the key symptom in nonemergency patients, but, in one-fourth of cases, CCF presents with an acute onset, mostly biliary ileus. In onefourth of patients, a second hepatobiliary abnormality is present, including gallbladder cancer in $2 \%$ of cases. In uncomplicated cases, diverting colostomy is not performed anymore, and laparoscopy treatment has been described in specialized centers. Symptomatic treatment of concomitant biliary ileus (without treating $\mathrm{CCF}$ ) is a feasible option.
\end{abstract}

R. Costi - T. Montariol

Service de Chirurgie Viscérale Digestive,

Urologique et Plastique, CHI Poissy/Saint-Germain-en-Laye,

Saint-Germain-en-Laye, France

R. Costi $(\bowtie) \cdot$ V. Violi $\cdot$ L. Sarli

Dipartimento di Scienze Chirurgiche, Università di Parma,

Via Gramsci 14, 43100 Parma, Italy

e-mail: renatocosti@hotmail.com

B. Randone - O. Scatton - O. Soubrane - B. Dousset Pole Medico-Chirurgical d'Hepato-Gastro-Enterologie, Hôpital Cochin, Assistance Publique-Hôpitaux de Paris, Université Paris-Descartes, Paris, France
Resolution of colonic biliary ileus by interventional endoscopy is reported.

Conclusion CCF should be considered in differential diagnosis of diarrhea, especially in old, female patients. A possible second hepatobiliary abnormality should be always investigated. Extemporaneous frozen section should be performed if gallbladder cancer is suspected. Depending on clinical presentation, different treatments for $\mathrm{CCF}$ are indicated, ranging from minimally invasive procedures to extensive resection.

Keywords Cholecystocolonic fistula - Biliary ileus . Diagnosis · Treatment · Laparoscopy

\section{Introduction}

Cholecystocolonic fistula (CCF) is a late complication of long-lasting gallstone disease and is found in roughly 1 in every 1,000 cholecystectomies. It is the second most common cholecystoenteric fistula after the cholecystoduodenal [1-3].

Symptoms of CCF are usually minimal and/or aspecific, and preoperative diagnostic tools often fail to show such a rare condition, hence diagnosis is often achieved intraoperatively [2,3]. Such a misdiagnosis may result in a challenging situation for the surgeon, who is forced to switch from an elective cholecystectomy to a complex procedure that usually involves adhesiolysis and colonic resection, possibly laparoscopically, often in old patients with comorbidities.

In order to make the surgeon aware of this uncommon but possible finding, and to identify the most effective diagnostic and surgical management of CCF, we present an extensive review of the literature on the subject. 


\section{Methods}

Using Medline, we matched the terms "fistula" and "gallstone ileus" with differently composed terms containing "gallbladder" or "biliary" or "cholecysto-" or "cholecystic" and "colon" or "colo-" or "colic" or "colonic." From selected articles, using links and references, we widened the search. All articles were considered regardless of language or impact factor. Papers reporting cholecystoenteric fistula or gallstone ileus in general were not considered in the paper, unless the peculiar features, diagnostic issues, and treatment of CCF were discussed separately. Data on the reported cases were taken from the full text, abstract, or title of the articles. Every effort was made to retrieve the entire article, by reviewing paper copies, by downloading from the official site of the reviews, or by directly contacting the authors. All papers were considered, apart from those without any specific reference to an individual case (for example, "CCF") or those manifestly reviewing the literature or referring to cases already reported by the same authors or by others (such as, for example, letters to the editor or replies).

We identified 160 articles from 1950 to 2006 concerning 231 cases of CCF, which are the object of our review [1160]. The analysis of diagnostic imaging and treatment is mainly focused on present tools, as proposed in recent papers. Owing to the heterogeneity of the sources, no statistical calculation was proposed regarding the whole series.

\section{Results}

The distribution of reported cases and scientific papers over the different decades is shown in Fig. 1.

\section{Epidemiology}

CCF represents from 8 to $26.5 \%$ of cholecystoenteric fistulas $[2,3,116]$, the second most common fistula after cholecystoduodenal. According to studies performed in large series of more than 10,000 patients undergoing cholecystectomy, the incidence of the fortuitous discovery of CCF during this procedure is reported to be $0.06-0.14 \%$ [1-3]. Female/male ratio in the series is $2.47 / 1$. Mean age of patients at diagnosis is reported as being 68.9 years (range 37-90), and, in particular, 70.8 years in Western papers and 62.1 in the Eastern ones.

\section{Etiology}

CCF is reported as complicating $0.13 \%$ of cases of acute cholecystitis [1]. Besides a chronic inflammatory process

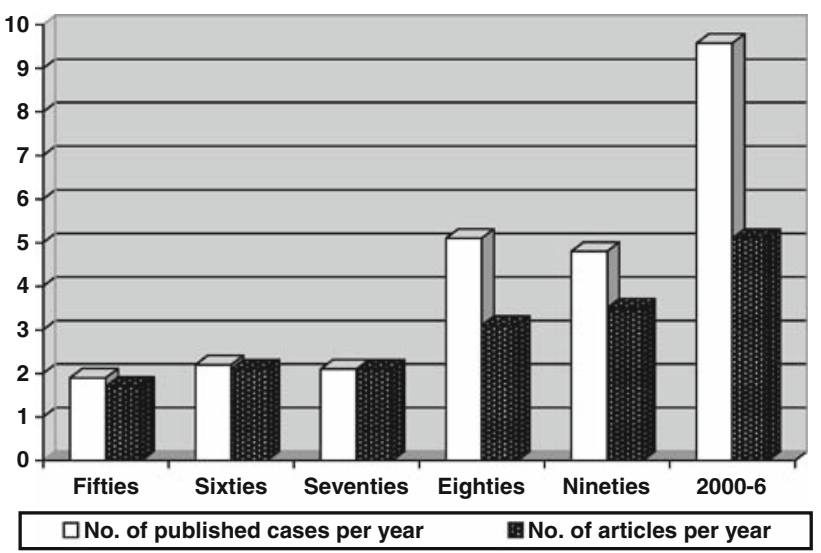

Fig. 1 Published cases and articles per year. Trend in publication of 160 articles regarding 231 cases of cholecystocolonic fistula from 1950 through 2006

of the gallbladder caused by gallstones, which is the most commonly described pathogenic mechanism for CF [1, 162], other factors have been reported as being associated with CCF in sporadic cases, such as previous surgery, namely gastric surgery $[90,100]$, cholecystostomy [25, 160], and traumatic or iatrogenic abdominal wounds [64, 67, 131]. Two cases of CCF formation following ascending colon afflictions have been reported: amoeboma [44] and diverticular disease [123]. In one case, a fistula involving the gallbladder, colon, and duodenum was reported to be due to a duodenal ulcer [12].

\section{Associations}

Supramesenteric afflictions and anomalies reported to be associated with CCF are shown in Table 1.

The onset: aspecific symptoms and life-threatening complications

Diarrhea is the most frequently reported symptom in the chronic onset of CCF $[13,15,18,27,33,42,79,91,100$, $110,112,120,123,141]$. Right hypochondrium pain [110, $123,147]$ and jaundice or fever (stigmata of cholangitis) $[91,112,123,147]$ are more rarely reported as relevant onset symptoms revealing CCF.

Acute onset complications are reported in Table 2. Obstruction (colonic biliary ileus) was reported to be the onset symptom in 42 cases of our series, in one case giving rise to a right-sided colonic perforation owing to caecum distension [120]. In all cases of colonic gallstone ileus but one [52], obstruction was caused by gallstone impaction in the sigmoid. Massive bleeding (often improperly defined as melena) was described in 14 patients and liver abscess in 4. 
Table 1 Supramesocolic anomalies/afflictions associated with cholecystocolonic fistulas

\begin{tabular}{ll}
\hline $\begin{array}{l}\text { Associated anomaly/ } \\
\text { affliction }^{\text {a }}\end{array}$ & No. References \\
& $(231$ \\
& total \\
& cases $)$ \\
\hline
\end{tabular}

\section{Various other fistulas}

Cholecystoduodenal $^{\mathrm{b}, \mathrm{c}} \quad 27$

[3], [7], [9], [12], [22], [23], [26], [27], [33], [35], [38], [39], [41], [45], [52], [53], [57], [64], [68], [69], [76],

[81], [87], [93], [95], [123]

\begin{tabular}{|c|c|c|}
\hline Cholecystogastric & 2 & [46], [118] \\
\hline Duodenocolic & 2 & {$[58],[81]$} \\
\hline Cholecystocholedochal & 1 & [76] \\
\hline $\begin{array}{l}\text { Cholecysto-internal } \\
\text { biliary duct }\end{array}$ & 1 & {$[137]$} \\
\hline Cholecystocutaneous & 1 & {$[160]$} \\
\hline Choledochoduodenal & 1 & [146] \\
\hline $\begin{array}{l}\text { Gastrocolonic (after } \\
\text { partial gastrectomy) }\end{array}$ & 1 & {$[100]$} \\
\hline Bronchobiliary & 1 & {$[58]$} \\
\hline \multicolumn{3}{|l|}{ Other CBD anomalies } \\
\hline CBD stone $\mathrm{e}^{\mathrm{d}, \mathrm{e}}$ & 12 & $\begin{array}{c}{[23],[35],[58],[78],[84],[91],} \\
{[92],[119],[146],[155]}\end{array}$ \\
\hline CBD polyp & 1 & {$[78]$} \\
\hline Gallbladder cancer $^{\mathrm{f}}$ & 4 & [49], [57], [111], [139] \\
\hline Liver abscess & 4 & [105], [108], [118], [139] \\
\hline \multicolumn{3}{|l|}{ Others } \\
\hline Double gallbladder & 1 & {$[61]$} \\
\hline $\begin{array}{l}\text { "Anomalous cystic } \\
\text { duct and artery" }\end{array}$ & 1 & [23] \\
\hline $\begin{array}{l}\text { Pseudoaneurysm } \\
\text { of cystic artery }\end{array}$ & 1 & {$[158]$} \\
\hline $\begin{array}{l}\text { Xanthogranulomatous } \\
\text { cholecystitis }\end{array}$ & 1 & [99] \\
\hline $\begin{array}{l}\text { Total anomalies } \\
\text { associated with CCF }\end{array}$ & 62 & $\begin{array}{l}\text { [3], [7], [9], [12], [22], [23], [26], } \\
{[27],[33],[35],[38],[39],[41],}\end{array}$ \\
\hline $\begin{array}{l}\text { Total patients with } \\
\text { anomalies associated } \\
\text { with } \mathrm{CCF}\end{array}$ & 56 & $\begin{array}{l}{[45],[46],[49],[52],[53],[57],} \\
{[58],[61],[64],[68],[69],[76],} \\
{[78],[81],[84],[87],[91-93],} \\
{[95],[99],[100],[105],[108],} \\
{[111],[118],[119],[123],[137],} \\
{[139],[146],[155],[158],[160]}\end{array}$ \\
\hline
\end{tabular}

$C B D$ Common bile duct, $C C F$ cholecystocolonic fistula

${ }^{\mathrm{a}}$ Any concurrent gallbladder stones are not reported

b Ref. [9], CCF was already closed when explored at surgery

${ }^{c}$ Ref. [95] reports two cases with such a feature

${ }^{\mathrm{d}}$ Concurrent, residual, or recurrent $(<1$ year) CBD stones are considered

e Refs. [84] and [91] report two cases with such a feature

${ }^{\mathrm{f}}$ Ref. [111]: squamous cell carcinoma tumor at histology; one or more anomalies may have been present in the same patient
Table 2 Complications of cholecystocolonic fistula giving rise to acute onset

\begin{tabular}{|c|c|c|}
\hline $\begin{array}{l}\text { Complication } \\
\text { causing acute } \\
\text { onset }\end{array}$ & $\begin{array}{l}\text { No. } \\
(231 \\
\text { total } \\
\text { cases })\end{array}$ & References \\
\hline 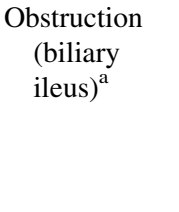 & 42 & $\begin{array}{l}\text { [11], [18], [21], [23], [50], [52], [58], [63], } \\
\text { [68], [69], [70], [73], [75], [76], [82], [83], } \\
\text { [88], [89], [95], [96], [102], [103], [106], } \\
\text { [113], [117], [119], [120], [125], [133], } \\
\text { [140], [142], [143], [147], [149], [150], } \\
\text { [153], [157], [159] }\end{array}$ \\
\hline $\begin{array}{l}\text { Massive } \\
\text { bleeding }\end{array}$ & 14 & $\begin{array}{l}\text { [17], [20], [28-31], [36], [51], [81], [97], } \\
\text { [139], [144], [148], [158] }\end{array}$ \\
\hline Liver abscess & 4 & [105], [108], [118], [139] \\
\hline Total & 60 & See above \\
\hline
\end{tabular}

$\overline{{ }^{a} \text { Refs. [11], [73], [76], and [113] report two cases of such a feature }}$

Imaging

\section{Preoperative}

Diagnosis of CCF is achieved preoperatively in only $7.9 \%$ of patients [3]. Pneumobilia at X-ray has been reported in some cases [90, 136], but not in others [20, 103]. Ultrasound (US) has very rarely been reported to be useful in CCF diagnosis [103, 137]. Barium enema has permitted the identification of CCF in some instances [107, 112, 122, 136], although false negatives are also reported [90, 91, 103, 123, 151]. Results of endoscopic retrograde cholangiopancreatography (ERCP) are variable, leading to diagnosis in some cases [90, 91, 112, 136-138, 155], but being useless in others $[109,110,112,121-123,151]$. Colonoscopy has more rarely been used and is reported to have identified a CCF in only a few cases $[43,94,103$, $133]$ but not in the rest [110, 122]. Scintigraphy is reported to have revealed CCF in some anecdotal cases $[54,71,91$, 105], and the same is true for CT scan [147, 148, 156], magnetic resonance [155], and endoscopic US [151].

\section{Intraoperative}

Few authors report intraoperative examinations as clarifying the status of gallbladder and common bile duct (CBD) and the possible presence of CCF or concomitant afflictions. Ibrahim [110] reported achieving a correct intraoperative diagnosis of CCF by injecting contrast in the gallbladder (intraoperative cholecystography). Intraoperative cholangiography is also reported to have led to the identification of concomitant CBD stones (see Table 1). 
Treatment

\section{Uncomplicated CCF}

Some aspects of recently proposed surgical treatments for uncomplicated CCF have been analyzed, namely the effectiveness of the laparoscopic procedure, the sequence of resections (cholecystectomy and colonic resection), the modality of colonic suturing, and the potential need for a diversion. Since 1994, 16 articles [2, 3, 104, 107, 109, 110, $114,121,122,127,129,132,135,146,152,155]$ have reported on laparoscopic (or laparo-assisted) [129] treatment of CCF in 36 elective patients. Owing to the nature of those articles, which were mostly case reports or large series including different types of bilio-enteric fistulas, data are largely incomplete, especially regarding duration of surgery. Some technical variations are reported regarding the modality of intracorporeal colonic suturing (manual $[121,132,160]$, mechanical $[2,104,114,155]$, or by the endoscopic device "endoloop" [2]). Some authors experienced intraoperative colonic leak [3, 121, 132], in three cases requiring conversion [3, 132]. The only reported postoperative major morbidity consisted of postoperative hemorrhage and subdiaphragmatic collection requiring drainage [3]. The reported duration of hospitalization is 7-18 days [3, 121, 122, 155].

Regarding the sequence of resections (colon and gallbladder), two variations are proposed: colon first $[104,110$, $114,135]$ and gallbladder first [1, 122, 123, 155]. Colostomy is no longer performed in cases of uncomplicated elective CCF surgery. Reddy [121] described a laparoscopic caecostomy after having witnessed an intraoperative colonic tear.

\section{Complicated CCF (emergency surgery and/or complex/ multiple fistula)}

Concerning the surgical procedure for massive bleeding from CCF, both colonic tangential resection [20, 29] and right colectomy [144] (in association with cholecystectomy) have been described (the latter in a case of a hemodynamically unstable patient).

Several options have been proposed in the case of emergency surgery for colonic gallstone ileus, such as decompression/exteriorization [162], enterolithotomy [120, 143], or segmental resection [1, 147]. Diverting colostomy is still largely performed in emergency cases to prevent further complications. In accordance with the required procedure and the surgeon's preference, several types of colostomy are reported (caecostomy [143], trasversostomy [23, 75, 153], or sigmoidostomy [120, 147]). In some instances [120, 144], right colectomy is required. The endoscopic extraction of a gallstone impacted in the sigmoid colon is reported to have allowed for emergency surgery to be avoided in two cases $[83,96]$.

The potential treatment of CCF (cholecystectomy/colonic resection) is reported to be accomplished contextually to the treatment for obstruction [142, 153] or during a second stage [63]. Several authors report a conservative attitude towards CCF after having dealt with colonic biliary ileus [91, 103, 120, 140, 143, 147].

In the case of patients presenting complex fistulas, several procedures on gallbladder and contiguous organs are reported, including cholecystostomy [1, 20, 68], atypical partial cholecystectomy (and Roux-en-Y hepaticojejunostomy) [137, 144], segmental [1, 81] or subtotal colectomy [149], and gastric partial resections [81, 118, 137].

\section{Discussion}

The interest in CCF has been increasing over the past half century, as documented by the number of cases reported and papers published on this subject since the 1950s (Fig. 1). The reason for such an interest is related to several factors: (1) preoperative diagnosis is rare, and intraoperative discovery is still a challenging situation to surgeons, who are asked to change the planned procedure (usually an elective cholecystectomy), often ignoring the features of this affliction and the ways to manage it; (2) improved technological means are proposed nowadays that allow for a preoperative diagnosis, in order to accomplish the most appropriate surgical treatment; (3) the advent of laparoscopy raises new questions regarding the possibility of achieving a correct diagnosis and accomplishing the entire procedure by this approach; and (4) (at least in Western countries) the aging of the population may be presumed to increase the interest in a condition that is usually discovered in the elderly.

Concerning this review, we arbitrarily decided to collect articles from 1950, since this is not a historical article but is aimed at reviewing clinical features, diagnostic tools, and treatment of CCF in modern times. Nevertheless, since in 1955 Deckoff [161] reported only 10 cases of colonic biliary ileus in the literature at that time, we estimate that our series represents the vast majority of CCF published cases.

Some epidemiologic aspects of CCF are worth a mention. Studies performed on large series (exceeding 10,000) of patients undergoing cholecystectomy report an actual reduction in the incidence of CCF since the early 1980s [1-3]. The reason for this variation (from 0.14 to $0.06 \%$ ) is probably related to the advent of laparoscopy. The worldwide diffusion of this technique, in fact, may be supposed to have given rise to an increase in the frequency of 
cholecystectomy at a younger age in the last two decades, reducing the number of patients undergoing cholecystectomy during their elderly years, when a long-lasting gallstone disease is more likely to cause CCF. Like other biliary-related afflictions, CCF is a condition mostly found in female patients.

It is worth underlining that age at diagnosis is more advanced in Western patients, mostly after age 65 (mean age about 71), than in Eastern patients, whose mean age at diagnosis is almost a decade younger (62). Moreover, even though cholecystoenteric fistula is considered a pathology related to old age, some sporadic cases of CCF before the age of $50[112,139]$ and even $40[23,65,147]$ have been reported in Western patients. Therefore, in our opinion, CCF should not be considered as being exclusive to the elderly.

Considering the etiology of $\mathrm{CCF}$, which is widely considered to be the final stage of a long-lasting inflammatory process of the gallbladder caused by gallstones (chronic or recurrent cholecystitis), it is somewhat interesting to note that inflammatory diseases of the colon, such as IBD, which are quite common afflictions with the tendency to fistulize to contiguous organs, have never been associated with CCF. In other words, with some anecdotal exceptions of rare pathologies [12, 44, 124], CCF always comes from the gallbladder.

A considerable number of patients (roughly one patient out of four-56/231 published cases) are reported as presenting synchronous supramesenteric afflictions (see Table 1), complicating the diagnosis and treatment of CCF. This incidence may be biased, since CCFs with unusual associations are more likely to be described in the literature. Nevertheless, the possible association of CCF with some other anomaly, usually cholecystoduodenal fistula (see Table 1) should be kept in mind. This data may prompt surgeons to utilize additional diagnostic tools preoperatively to rule out the potential presence of other anomalies (ERCP, CT scan) and possibly to modify their strategy. If incidentally discovered at surgery, CCF should prompt surgeons to explore the region and to perform intraoperative examinations, such as intraoperative US or cholangiography $[1,110]$.

Although not frequent, the association with gallbladder carcinoma is worth considering for several reasons. The reported incidence of CCF (about 0.1\%) [1-3] is comparable with that of the fortuitous finding of carcinoma in a gallbladder excised for lithiasis (0.3\%) [162]; this fact is particularly interesting if we consider that the intraoperative differential diagnosis between the two afflictions is often not easy, and that, as reported in our series, the two conditions may coexist in the same patient $[49,57,111$, 139]. If we consider this association to be random, it should be present in three cases out of every million (the incidence of unsuspected $\mathrm{CCF}$ and gallbladder cancer cholecystectomies being 0.1 and $0.3 \%$, respectively), while the literature reports four gallbladder carcinomas out of 231 cases of CCF. Consequently, in our opinion, the finding of a hard-to-dissect, fistulized-to-colon gallbladder should prompt the surgeon to take a frozen section of the specimen. Interestingly, some large surveys considering patients presenting with cholecystoenteric fistula in general $[1,163]$ report an even higher rate of cancer associated with fistula (3-14\%). In accordance with these data, we agree with Prasad and Foley [104], who suggest considering a safety margin during colonic resection for $\mathrm{CCF}$, since gallbladder cancer could possibly coexist.

Although the triad of symptoms-diarrhea, right hypocondrium pain, and cholangitis (jaundice/fever) - is generally considered as being the typical clinical picture of $\mathrm{CCF}$ at the onset, analysis of the literature revealed some surprising data. Due to the laxative effects of bile acids that bypass the distal ileum and reach the transverse colon unabsorbed, diarrhea is by far the most frequent symptom in nonemergency-onset CCF $[13,15,18,27,33,42,79,91$, $100,110,112,120,123,141]$. In a review of patients affected by CCF, Hession [112] found diarrhea to be the dominant symptom in $71 \%$ of cases. Moreover, it should be noted that the severity of diarrhea may also induce a malabsorptive syndrome [32, 40,60], which may also be responsible for megaloblastic anemia $[26,92]$ as well as osteomalacia, fracture of the pelvis, ventricular tachycardia, and chronic heart failure [92].

In contrast, right hypochondrium pain, which is the most frequent symptom in large series of patients affected by cholecystoenteric fistulas in general [3], is rarely reported to dominate the clinical picture in the case of CCF [110, 123, 147]. Similarly, even though a CCF fistula is supposed to carry a high potential for infection of the gallbladder and biliary system, jaundice and fever, the typical marks of cholangitis [1] are rarely reported as onset symptoms of CCF [91, 112, 123, 147]. From our review of the literature, diarrhea, although nonspecific, should be considered the only real key symptom of CCF.

$\mathrm{CCF}$ is generally considered not to predispose patients to biliary ileus, which is the most common complication of proximal fistulas [161]. In fact, the stone-eventually migrating from the gallbladder-is presumed to bypass the Bahuin's valve, thus being easily expelled with stools. Surprisingly, in approximately one case out of five (42/ 231), patients with CCF presented occlusion by biliary ileus. Other causes of acute onset of symptoms are massive bleeding and liver abscess, afflicting a total of 60 patients presenting with emergency complications (see Table 2). Our findings somewhat match the features of the literature, which report CCF as constituting $15 \%$ of cholecystoenteric 
fistulas [110] and as causing $4.8 \%$ of gallstone ileus cases [164].

In the vast majority of patients considered from 1950 onward, biliary ileus was located at the sigmoid colon. The size of the stone is presumed to determine whether and where a migrated stone will impact. Small and mid-sized stones are thought to pass through the entire colon, whereas gallstones over $2.5 \mathrm{~cm}$ in diameter may cause colonic obstruction at the sigmoid colon [1, 73]. In fact, only exceptional cases of "giant" stones impacted in the colon proximally to the sigmoid (descending colon [149], transverse colon [165]) or of smaller stones passing through the sigmoid and impacting in the rectum [166] are reported.

In elderly patients, intestinal obstruction by a gallstone impacted in the sigmoid may evidently be mistaken for other more common causes of distal colonic obstruction such as cancer and chronic diverticulitis, misleading diagnosis [101]. In conclusion, if the patient is elderly, female, affected by gallbladder lithiasis and presenting a distal colon obstruction (sigmoid), colonic biliary ileus (associated with CCF) should be considered in differential diagnosis.

There may be differing reasons why such a low preoperative diagnosis rate occurs in CCF patients (less than $10 \%$ [3], compared to $43 \%$ of series reporting cholecystoenteric fistulas in general [1]). Other than the nonspecificity of symptoms, the very low percentage of preoperative diagnosis of CCFs may be attributed to the inefficacy of diagnostic means. None of the imaging techniques, from old to modern ones, have shown great accuracy in recognizing CCF. The pathognomonic radiological sign of pneumobilia at plane radiography, which represented the gold standard of diagnosis of bilioenteric fistula for decades [167], is often absent [20, 103]. US, which is considered a first-level tool especially when a hepato-biliary condition is suspected, has been reported to give information as to CCF only rarely [103, 137]. Barium enema is reported to have led to the majority of preoperative diagnoses $[107,112,122,136]$, but has shown low sensitivity [90, 91, 103, 123, 151]. Endoscopic tools, namely ERCP and colonoscopy, have recently been reported to show CCF in sporadic cases, but their results are extremely variable $[43,94,109,110,112,121,138$, 151, 155]. Moreover, owing to their (relative) invasiveness, these procedures are not immediately or routinely requested for patients with nonspecific or ambiguous symptoms. Similarly, although liver scintigraphy [54, 71], magnetic resonance [155], and endoscopic US [151] are reported to reveal CCF in some anecdotal cases, they are not considered as being easy-access examinations for patients with diarrhea or mild abdominal pain. Surprisingly, CT scan has seldom been reported in the preoperative work-up of undiagnosed CCF [147, 156], unless gallstone ileus is present [140]. In general, it should be remarked that none of the diagnostic tools available alone consistently led to the identification of CCF. In the rare cases where CCF was identified preoperatively, diagnosis was made after several exams were performed until one of them identified CCF.

A heterogeneous variety of approaches is reported for the treatment of $\mathrm{CCF}$, ranging from sphincterotomy alone [80, 91] to major colonic [1, 81, 120, 147, 149] or gastric resection [81, 137]. In uncomplicated patients, in the last decades, CCF therapy has become less and less aggressive. Some authors propose endoscopic treatment of CCF in the case of patients with poor general condition or with concomitant CBD stones, since the treatment for choledocholithiasis by sphincterotomy may encourage $\mathrm{CCF}$ closure by reducing bile pressure in the gallbladder [80, 91]. Conversely, if elective surgical treatment of CCF is indicated, a few main issues emerge from the analysis of recent literature regarding the need for a temporary colostomy, the feasibility of CCF closure by laparoscopy, and technical aspects of the surgical act.

Traditional teaching suggests a "two-stage" procedure (involving a diverting colostomy). At least since the early 1980s, however, unless an intraoperative complication occurs [121], "one-step" management has been considered the treatment of choice [1] without significant complications being reported [2, 3, 104].

Cholecystoenteric fistula was considered a formal contraindication to the laparoscopic approach until the early 1990s [168]. Recently, laparoscopic procedures have been proposed for patients with CCF [2, 3, 104, 107, 109, $110,114,121,122,127,129,132,135,146,152,155]$. Although these authors support the feasibility of the entire procedure by the laparoscopic approach, some of them report long operating times and, despite the small series of patients, a considerable number of conversions [3, 132], in some cases due to iatrogenic colonic perforation [3]. Despite a recent trend towards the laparoscopic accomplishment of the procedure for cholecystoenteric fistula, a multicenter study [2] reports early conversion in $55 \%$ of patients. Indeed, the avulsion of cholecystoenteric fistulas during laparoscopic blunt dissection is not a rare event [3], and its intraoperative management (intracorporeal "manual" suture) may be a demanding skill for average laparoscopic surgeons to perform on a malacic colonic wall. Since the vast majority of patients presenting with cholecystodigestive fistulas are old and often in poor general condition, and $\mathrm{CCF}$ is reported to have a high mortality rate in this class of patients [27, 36, 164], we do not believe that a minimally invasive approach should be considered as being a major issue in these cases. In our opinion, in this class of patients, the supposed advantages of a minimally invasive approach 
should be balanced against longer operative times and possible intraoperative complications of laparoscopy. Thus, the laparoscopic management of such a condition should be carefully evaluated case-by-case and surgeonby-surgeon. In any case, if required, conversion should not be postponed.

Regardless of the modality of approach (laparotomy or laparoscopy), several technical variations have been proposed in standard situations (uncomplicated CCF), regarding the sequence of gallbladder and colonic resections and the "manual" $[121,132,160]$ or "mechanical" $[2,104,114,155]$ modality of colonic resection. Since no complications related to any of them have been documented, all these techniques should be considered as being equally effective. Finally, as already pointed out by others $[1,2]$, we believe that CBD exploration (intraoperative cholangiography) should always be performed, since CBD stones may coexist (see Table 2). If CBD stones are discovered preoperatively, some authors $[80,91]$ maintain that it is not necessary to treat CCF after endoscopic sphincterotomy, since $\mathrm{CCF}$ is presumed to regress once choledocholithiasis has been treated.

The treatment of emergency complications of CCF or complex fistulas may be more troublesome. Whereas a onestage classic procedure (colonic tangential resection and cholecystectomy) is considered as being the treatment of reference for massive hemorrhage by CCF [20,29], several options have been proposed in the case of obstruction or complex/multiple fistulas. In the case of colonic gallstone ileus, the main purpose of emergency surgery (so-called first stage) is to resolve the obstruction [63]. Nowadays, in the case of colonic ileus, this may be achieved by enterolithotomy [142] or segmental resection [147], according to sigmoid status. It should be stressed that a complete exploration of the GI tract should be performed, since concurrent colonic stones [120] or caecum perforation [144] may be present. Regarding temporary diversion, although most recent papers still report colostomy in the treatment of gallstone ileus [120, 143, 147, 153], some consider diversion not to be always necessary [140]. In our opinion, the need for a colostomy should be evaluated on a case-by-case basis.

The need and (possibly) the timing for the treatment of cholecystoenteric fistula are also a matter of discussion concerning patients with gallstone ileus [95, 163, 164]. Even in recent papers on the management of colonic gallstone ileus, it is debated whether to perform cholecystectomy at the same time [120], as a delayed procedure [147], or not at all [103, 143], at least until symptoms recur.

Although the treatment of the obstruction is usually accomplished surgically and implies at least a colotomy for the extraction of the stone, the peculiar location of the obstacle (sigmoid) is reported to have allowed for retrieval of the gallstone by endoscopy in some cases [83, 96], avoiding emergency surgery. In two other cases, the gallstone was "spontaneously" expelled after an unsuccessful endoscopic attempt $[133,150]$. Although a few sporadic cases are not sufficient to allow for any generalization, these papers suggest that it could be worth a try to resolve colonic biliary ileus by colonoscopy before performing emergency surgery. This approach is even more interesting for patients in poor general condition, where this procedure may be presumed to allow for a delayed "one-stage" laparoscopic elective surgical procedure for CCF closure, or for no surgery at all, if we admit that the fistulous tract may spontaneously close after the obstruction has resolved [103, 147].

An even wider variety of surgical procedures is reported for complex and multiple fistulas. The unclear anatomy of the gallbladder loggia, owing to intense scarring and adhesions, is reported to require procedures on the gallbladder that are nowadays unusual, such as cholecystostomy [1, 20, 68] or atypical partial cholecystectomy with cholecystojejunal derivation [137, 144]. Furthermore, the effect of such a long-lasting inflammatory process on the gallbladder and contiguous viscera is unpredictable preoperatively and may give rise to a very challenging situation for surgeons, as witnessed by major colonic [1, 81, 149] and gastric resections [81, 118, 137] reported in complex cases.

In conclusion, on the basis of the findings of this extensive review, we summarize the following points:

- Mean age of CCF at diagnosis is 71 years in Western populations and 62 years in Eastern populations. Young age $(<50$ years) does not necessarily rule out CCF.

- Diarrhea is the key symptom of uncomplicated CCF.

- Acute onset of symptoms does not necessarily rule out CCF, since it may manifest with biliary ileus, massive lower hemorrhage, or liver abscess. The site of impaction of colonic gallstone ileus is almost exclusively the sigmoid.

- None of the preoperative diagnostic tools has shown great sensitivity. If CCF is suspected but not confirmed at imaging, the indication is to proceed with all exams available.

- Preoperative or intraoperative discovery of CCF should alert surgeons and lead them to explore the hepatic loggia, since a second hepatobiliary affliction/anomaly may be present. Intraoperative (or postoperative) examinations should be performed.

- If any uncertainty remains regarding differential diagnosis between $\mathrm{CCF}$ and gallbladder cancer, extemporaneous frozen section should be performed, and a 
security margin during tangential colonic resection should always be respected.

- Diverting colostomy may be avoided in uncomplicated cases.

- Laparoscopy is equivalent to laparotomy, in uncomplicated cases, if managed by experienced laparoscopic surgeons, although increased operating time and conversion rate are probably to be expected.

- In stable patients, resolution of colonic biliary ileus may be worth a try by endoscopic retrieval of the gallstone (colonoscopy).

- In emergency/complicated cases, the appropriate treatment should be "custom made," major GI viscera demolition may be required, and deciding not to resolve CCF is a feasible option.

\section{References}

1. Glenn F, Reed C, Grafe WR. Biliary enteric fistula. Surg Gynecol Obstet. 1981;153:527-31.

2. Angrisani L, Corcione F, Tartaglia A, Tricarico A, Rendano F, Vincenti $\mathrm{R}$, et al. Cholecystoenteric fistula $(\mathrm{CF})$ is not a contraindication for laparoscopic surgery. Surg Endosc. 2001;15:1038-41.

3. Chowbey PK, Bandyopadhyay SK, Sharma A, Khullar R, Soni V, Baijal M. Laparoscopic management of cholecystoenteric fistulas. J Laparoendosc Adv Surg Tech A. 2006;16:467-72.

4. Castro AF, Ault GW, Smith RS. Cholecystocolic fistula; report of a case. Med Ann Dist Columbia. 1950;19:495-8.

5. Delore P, Chapuy A, Madona. Evacuation of large vesicular calculus by cholecystocolic fistula. Arch Mal Appar Dig Mal Nutr. 1950;39:740.

6. Michels AG, Hoerr SO. Spontaneous internal biliary fistula; a case of cholecystocolic fistula. Cleve Clin Q. 1951;18:184-9.

7. Lapeyre NC, Campo A, Carabalona P. Spontaneous bilio-intestinal double perforation; associated lithiasic fistulae, cholecystoduodenal and cholecysto-colic. Montp Med. 1951;39-40:240-2.

8. Calihan WA, Hulbert HF. Intestinal obstruction due to gallstones; report of two cases. J Int Coll Surg. 1951;16:325-33.

9. Deroche R, Cabon P. Unusual case of cholecystocolic fistula. J Radiol Electrol Arch Electr Med. 1953;34:769.

10. Neville WE. Duodenocolic fistula due to acute cholecystitis. Am J Surg. 1953;87:300-2.

11. Paulini WL. Two cases of ileus due to gallstone in colon. Ned Tijdschr Geneeskd. 1953;97:1125-6.

12. Craighead CC, Raymond AH Jr. With special reference to choledochoduodenal fistula complicating duodenal ulcer. Am J Surg. 1954;87:523-33.

13. Rosenqvist H, Sjoberg SG. Duodeno-colic fistulas. Acta Chir Scand. 1955;109:293-8.

14. Liberti V, Garlano M. Histopathological alterations of the liver, gallbladder, pancreas, spleen and colon in cholecystocolic fistula; preliminary note. Riv Patol Clin. 1956;11:412-4.

15. Levrat M, Bret P, Romier H, Grivet A. Cholecystocolic fistula with cholelithiasis causing chronic diarrhea. Arch Mal Appar Dig Mal Nutr. 1957;46:879-86.

16. Lampe CE. Obstruction of the colon by gallstones; report of a case and analysis of 20 cases of gallstone ileus with special reference to roentgen diagnosis. Ugeskr Laeger. 1957;119:121-4.
17. De Keyser R. Hemorrhagic diathesis with cholecystocolic fistula. Belg Tijdschr Geneesk. 1958;14:195-7.

18. Eilersen P, Kjeldsen K. Steatorrhea caused by cholecystocolic fistula. Ugeskr Laeger. 1959;121:378-80.

19. Delannoy E, Martinot M. Choledochal lithiasis complicated by broncho-biliary and cholecysto-colic fistulae. Role of elevated pressure in the bile ducts. Lyon Chir. 1959;55:801-6.

20. Chaffee JS. Cholecystocolic fistula with large bowel hemorrhage. Case report. Ann Surg. 1960;152:901-4.

21. Young WV Jr. Gallstone ileus of the colon. Report of an unusual type of colon obstruction. Arch Surg. 1961;82:333-6.

22. Edmunds PK, Havard C. Duodeno-colic fistula due to gallstones. Br J Surg. 1961;49:253-5.

23. Levowitz BS. Spontaneous internal biliary fistulas. Ann Surg. 1961;154:241-51.

24. Pasquier V. Apropos of a case of cholecystocolic fistula. Lyon Chir. 1962;58:768-70.

25. Hutchin P, Harrison TS, Halasz NA. Cholecystocolic fistula: a complication of cholecystostomy; with special reference to the management of cholecystostomy. Ann Surg. 1963;157:587-90.

26. Isherwood I, MacCaig J. Cholecysto-duodeno-colic fistula presenting with megaloblastic anaemia. Clin Radiol. 1963;14:91-3.

27. Dowse JL. Cholecysto-duodenocolic fistulae due to gall-stones. Br J Surg. 1963;50:776-8.

28. Welti H, Epfelbaum R, Gibert G. Spontaneous cholecysto-colic biliary fistula: cataclysmic hemorrhage from ulceration of the cystic artery. Mem Acad Chir (Paris). 1964;90:932-5.

29. Zisk J, Furman GN, Morgenstern L. Massive rectal bleeding from a cholecystocolic fistula. Calif Med. 1964;100:370-1.

30. Lauras H. Pseudo-cancerous cholecysto-colic fistula with profuse hemorrhage. Mem Acad Chir (Paris). 1965;91:271-2.

31. Bastien J, Hartglas L. A case of cholecystocolic fistula with cataclysmic hemorrhage. Mem Acad Chir (Paris). 1965;91:5414.

32. Elsas LJ, Gilat T. Cholecystocolonic fistula with malabsorption. Ann Intern Med. 1965;63:481-6.

33. Pedersen SN. Cholecysto-duodeno-colic fistula. Report of a case. Acta Chir Scand. 1965;129:452-6.

34. Stanciu G. Radiologic study of a cholecystocolic fistula. J Radiol Electrol Med Nucl. 1966;47:427-8.

35. Nemhauser GM, Thompson JC. Cholecystoduodenocolic fistula due to gallstones: case report. Ann Surg. 1966;163:81-5.

36. Kaplan BJ. Massive lower gastrointestinal hemorrhage from cholecystocolic fistula. Dis Colon Rectum. 1967;10:191-6.

37. Gudas PP Jr, Haberman GC, Belcher HV. Cholecystocolonic fistula. Arch Surg. 1967;95:228-9.

38. Hureau J, Bourdais JP, Vayre P, Levasseur JC. A case of duodeno-cholecysto-colic fistula of lithiasic origin. Sem Hop. 1968:44:1979-81.

39. Birnbaum JJ, Tolins SH. Cholecystoduodenal and cholecystocolonic fistula: report of a case and review of the literature. Mt Sinai J Med. 1970;37:625-31.

40. Augur NA Jr, Gracie WA Jr. Cholecystocolonic fistula associated with malabsorption. Am J Gastroenterol. 1970;53:558-63.

41. Shocket E, Evans J, Jonas S. Cholecysto-duodeno-colic fistula with gallstone ileus. Arch Surg. 1970;101:523-6.

42. Grossman ET. Cholecystocolic-fistula - an unusual cause of diarrhoea. Am J Gastroenterol. 1971;55:277-83.

43. Ianacone JA, Becker GL Sr. Diagnosis of a cholecystocolic fistula by sigmoidoscopy and serendipity. J Med Soc N J. 1971;68:215-8.

44. Menda RK, Chulani HL. Cholecystocolonic fistula following ameboma of the ascending colon: report of a case. Dis Colon Rectum. 1971;14:386-8.

45. Wise WS, Caldwell FT. Cholecystoduodenocolic fistula. Am J Surg. 1971;121:349-50. 
46. Piedad OH, Walczak PM. Cholecystogastrocolic fistula. N Y State J Med. 1972;72:388-9.

47. Aznar Reig A. Spontaneous disappearance of a large biliary calculus. Biliary-colic fistula. Rev Esp Enferm Apar Dig. 1973;41:255-66.

48. Safaie-Shirazi S, Zike WL, Printen KJ. Spontaneous enterobiliary fistulas. Surg Gynecol Obstet. 1973;137:769-72.

49. Godquin B, Favre R, Blanchard J, Boutovitch N. A cholecystocolic fistula caused by perforation of a gallbladder cancer. Case report. Acta Gastroenterol Belg. 1974;37:236-42.

50. Balsano NA, Reynolds BM. Cholecystocolic fistula with colonic obstruction: report of a case. Dis Colon Rectum. 1974;17:766-8.

51. Olteanu C, Socoteanu I. Gallbladder lithiasis complicated by a cholecystocolonic fistula and digestive haemorrhage. Chirurgia (Bucur). 1974;23:141-4.

52. Doromal NM, Estacio R, Sherman H. Cholecysto-duodeno-colic fistula with gallstone ileus: report of a case. Dis Colon Rectum. 1975;18:702-5.

53. Marsault C, Drouard F, Gaussin G. A rare case of double biliary fistula. J Radiol Electrol Med Nucl. 1977;58:657-8.

54. Zaw-win B, Darwish M, Dibos PE, Razzak IA. I131-rose bengal scanning in the detection of cholecystocolic fistula. New use of an established procedure. Am J Gastroenterol. 1977;68:396-8.

55. Mrozowski A, Malinowski S. Preoperatively diagnosed cholecystocolonic fistula. Pol Tyg Lek. 1977;32:537-8.

56. Raya Munoz J, Gil Extremera B, Garcia Romero E, Salmeron Escobar J, Sanchez Alcala B. A case of pyloric stenosis caused by biliary calculi and a double biliary-duodenal and biliarycolonic fistula. Rev Esp Enferm Apar Dig. 1977;51:211-8.

57. Morris SJ, Greenwald RA, Barkin JS, Tedesco FJ, Snyder R. Cholecystoduodenocolic fistula secondary to carcinoma of the gallbladder. Am J Dig Dis. 1978;23:849-52.

58. Hricak H, Vander Molen RL. The radiology corner: duodenocolonic fistula with gallstone ileus. Am J Gastroenterol. 1978;69:711-5.

59. Faintuch J, Martini AC, Machado MC, Raia AA. Clinico-surgical repercussions of cholecystocolic fistula. Rev Hosp Clin Fac Med Sao Paulo. 1979;34:289-93.

60. Rau WS, Matern S, Gerok W, Wenz W. Spontaneous cholecystocolonic fistula: a model situation for bile acid diarrhoea and fatty acid diarrhoea as a consequence of a disturbed enterohepatic circulation of bile acids. Hepatogastroenterology. 1980;27:231-7.

61. Ritchie AW, Crucioli V. Double gallbladder with cholecystocolic fistula: a case report. Br J Surg. 1980;67:145-6.

62. Edell SL, Milunsky C, Garren L. Cholescintigraphic diagnosis of cholecystocolic fistula. Clin Nucl Med. 1981;6:303-4.

63. Anseline P. Colonic gall-stone ileus. Postgrad Med J. 1981;57:62-5.

64. Griffith CD, Saunders JH. Cholecystoduodenocolic fistula following abdominal trauma. Br J Surg. 1982;69:99-100.

65. Bates GJ, Askew AR. Cholecystocolic fistula in a young woman. Med J Aust. 1983;2:11-2.

66. White M, Simeone JF, Muller PR. Imaging of cholecystocolic fistulas. J Ultrasound Med. 1983;2:181-5.

67. Mittelstaedt WE, Carone Filho E, Sekini JH, Deutsch CR, Neri JR, Pires PW, et al. Bilio-digestive fistulas. Arq Gastroenterol. 1984;21:3-12.

68. Pangan JC, Estrada R, Rosales R. Cholecystoduodenocolic fistula with recurrent gallstone ileus. Arch Surg. 1984;119:1201-3.

69. Gibbons CP, Ross B. Cholecystoduodenocolic fistula and gallstone ileus. Postgrad Med J. 1984;60:698-9.

70. Jensen LS, Falstie-Jensen S. Gallstone-induced colonic ileus. Ugeskr Laeger. 1984;146:2706.

71. Takada T, Yasuda H, Uchiyama K, Hasegawa H, Kuniyasu Y, Higashi S, et al. A case of cholecystocolic fistula demonstrated with 99mTc-PMT imaging. Rinsho Hoshasen. 1985;30:617-20.
72. Ripley SD, Fink-Bennett D. Enterobiliary fistulae: a potential cause of a false-negative hepatobiliary study in the diagnosis of acute cholecystitis. Eur J Nucl Med. 1985;10:167-8.

73. Milsom JW, MacKeigan JM. Gallstone obstruction of the colon. Report of two cases and review of management. Dis Colon Rectum. 1985;28:367-70.

74. Rosenberg RJ, Sziklas JJ, Spencer RP, Mathews J. Gallbladder to colon fistula demonstrated on hepatobiliary study. Clin Nucl Med. 1985;10:727.

75. Deitz DM, Standage BA, Pinson CW, McConnell DB, Krippaehne WW. Improving the outcome in gallstone ileus. Am J Surg. 1986;151:572-6.

76. Van Gossum M, Fastrez R, Issa S, Burette A, Nyst JF, Deltenre M. Cholecystoduodenocolic fistula and gallstone ileus. Acta Gastroenterol Belg. 1986;49:624-7.

77. Colovic R, Dordevic D, Colovic M. Cholecysto-colonic fistula (2 case reports). Acta Chir Iugosl. 1987;34:160-6.

78. Lautatzis M, Shoenut JP, Scurrah J, Micflikier AB. Pseudocalculus of the common bile duct. Can J Surg. 1988;31:37-8.

79. Mishra GK, Vernekar J, Pandey M, Gupta A. Fatty diarrhoea due to spontaneous cholecystocolonic fistula. J Assoc Physicians India. 1988;36:176-7.

80. Goldberg RI, Phillips RS, Barkin JS. Spontaneous cholecystocolonic fistula treated by endoscopic sphincterotomy. Gastrointest Endosc. 1988;34:55-6.

81. Giglio P, Cossavella D, Bosco L. A rare case of spontaneous cholecysto-choledocho-duodenocolic fistula. Minerva Chir. 1988;43:721-3.

82. Caramanico L, Gianferro A, Occhigrossi G, Costi U, Izzo L, Smaldone W. Biliary ileus located in the sigmoid. Minerva Chir. 1988;43:1631-4.

83. Patel SA, Engel JJ, Fine MS. Role of colonoscopy in gallstone ileus-a case report. Endoscopy. 1989;21:291-2.

84. Tubia Landaberea JI, Palomar LM, Cormenzana Lizarribar E, Beguiristain Gomez A, Rocandio Cilveti E, Alvarez Caperochipi J. Spontaneous cholecystocolonic fistulas. Presentation of 5 cases. Rev Esp Enferm Apar Dig. 1989;75:192-7.

85. Kadyrov ZL. Cholelithiasis complicated by cholecysto-colonic fistula. Vestn Khir Im I I Grek. 1989;142:7.

86. Chaikovskii IuIa, Kornev VM, Sharov NA, I'lin SV. Cholecysto-colonic fistula as a complication of cholelithiasis. Vestn Khir Im I I Grek. 1989;142:6.

87. Lim BH, Mack P, Mohan C. Cholecysto-duodeno-colic fistulaa case report. Ann Acad Med Singapore. 1989;18:296-7.

88. Braun L. Gallstone ileus. Incidence, clinical aspects, therapy. Chirurg. 1989;60:545-8.

89. Serrano R, Montanana A, Lacasa J. Cholelithiasis and cholecysto-colonic fistula: a rare form of biliary ileus. Rev Esp Enferm Dig. 1990;77:55-7.

90. Sing RF, Garberman SF, Frankel AM, Chatzinoff M. Cholecystocolic fistula: an unusual presentation and diagnosis by endoscopic retrograde cholangiopancreatography. Surg Endosc. 1990;4:39-40.

91. Caroli-Bosc FX, Ferrero JM, Grimaldi C, Dumas R, Arpurt JP, Delmont J. Cholecystocolic fistula: from symptoms to diagnosis. Gastroenterol Clin Biol. 1990;14:767-70.

92. Benage D, O'Connor KW. Cholecystocolonic fistula: malabsorptive consequences of lost bile acids. J Clin Gastroenterol. 1990;12:192-4.

93. Leong S. Cholecysto-duodenocolic fistula-a case report. Ann Acad Med Singapore. 1990;19:421.

94. Sakurai Y, Itoh M, Tsuchiya H, Ikegami F, Takasu S, Izumi T, et al. Acute cholecystocolic fistula detected by colonoscopy. Gastrointest Endosc. 1990;36:163-4.

95. Clavien PA, Richon J, Burgan S, Rohner A. Gallstone ileus. Br J Surg. 1990;77:737-42. 
96. Roberts SR, Chang C, Chapman T, Koontz PG Jr, Early GL. Colonoscopic removal of a gallstone obstructing the sigmoid colon. J Tenn Med Assoc. 1990;83:18-9.

97. Miguil M, Abassi O, Margad B, Harti A, Benslama A, Benaguida M. Severe hemobilia of cholecystic origin. J Chir (Paris). 1991;128:83-5.

98. Catalano O. Echographic nonvisualization of the gallbladder in a case of cholecysto-colic fistula. Radiol Med (Torino). 1992;84:489-90.

99. Rosell Pradas J, Andujar Sanchez M, Martin Ruiz JL, Mantas Avila JA, Morales Valentin OI, Guerrero Fernandez-Marcote JA, et al. Xanthogranulomatous cholecystitis. Rev Esp Enferm Dig. 1992;82:334-8.

100. Wagtmans M, Kooy M, Snel P. Persistent diarrhoea in cholecystocolic and gastrocolic fistula after gastric surgery. Neth $\mathbf{J}$ Med. 1993;43:218-21.

101. Gerst PH, Katter H, Rosario PG. Cholecystocolic fistula masquerading as colon cancer. Am J Gastroenterol. 1993;88:1296-7.

102. Catalano O, Rotondo A. Biliary ileus of the sigmoid: its echographic diagnosis. A case report. Radiol Med (Torino). 1994;87:519-20.

103. Swinnen L, Sainte T. Colonic gallstone ileus. J Belge Radiol. 1994;77:272-4.

104. Prasad A, Foley RJ. Laparoscopic management of cholecystocolic fistula. Br J Surg. 1994;81:1789-90.

105. Anez LF, Gupta SM. Cholescintigraphy detection of cholecystocolonic fistula and liver abscess. Clin Nucl Med. 1994;19:551-2.

106. Figarella J, Campan P, Lecoq C. A case of biliary ileus of the colon. J Chir (Paris). 1994;131:330-1.

107. Gentileschi P, Forlini A, Rossi P, Bacaro D, Zoffoli M, Gentileschi E. Laparoscopic approach to cholecystocolic fistula: report of a case. J Laparoendosc Surg. 1995;5:413-7.

108. Seto H, Watanabe N, Kageyama M, Shimizu M, Nagayoshi T, Kamisaki Y, et al. Concurrent detection of cholecystocolic fistula and hepatic abscess by hepatobiliary scintigraphy. Ann Nucl Med. 1995;9:93-5.

109. Williams J, Deans G, Royston C, Brough W. Laparoscopic management of cholecystocolic fistula. Br J Surg. 1995;82:565.

110. Ibrahim IM, Wolodiger F, Saber AA, Dennery B. Treatment of cholecystocolonic fistula by laparoscopy. Surg Endosc. 1995;9:728-9.

111. Khaira HS, Awad RW, Thompson AK. Squamous cell carcinoma of the gallbladder presenting with a biliary-colic fistula. Eur J Surg Oncol. 1995;21:581-2.

112. Hession PR, Rawlinson J, Hall JR, Keating JP, Guyer PB. The clinical and radiological features of cholecystocolic fistulae. Br J Radiol. 1996;69:804-9.

113. Perez Morera A, Perez Diaz D, Calvo Serrano M, de Fuenmayor Valera ML, Martin Merino R, Turegano Fuentes F, et al. Acute obstruction of the colon secondary to biliary lithiasis. Rev Esp Enferm Dig. 1996;88:805-8.

114. Pianalto S, Rossi M, Battaglia G, Pizzato D, Ancona E. Cholecysto-colic fistula: laparoscopic treatment. Ann Ital Chir. 1997;68:231-3.

115. Sirakov M, Trichkov V, Megdanski KH. Spontaneous internal biliary fistulae-a report of 4 clinical cases. Khirurgiia (Sofiia). 1997;50:16-8.

116. Yamashita H, Chijiiwa K, Ogawa Y, Kuroki S, Tanaka M. The internal biliary fistula - reappraisal of incidence, type, diagnosis and management of 33 consecutive cases. HPB Surg. 1997;10:143-7.

117. Foster DR. Colonic gallstone ileus. Australas Radiol. 1997;41:76-7.

118. Hakim M, Boyd R, Stricoff R, Shaftan G, Saxe A. Cholecystogastrocolonic fistula with intrahepatic abscess: a rare complication of biliary stone disease. Am Surg. 1997;63:472-4.
119. Andersen PS, Petersen JK. Colonic ileus caused by a giant gallstone. Ugeskr Laeger. 1998;160:4653-4.

120. Bornet G, Chiavassa H, Galy-Fourcade D, Jarlaud T, Sans N, Labbe F, et al. Biliary colonic ileus: an unusual cause of colonic obstruction. J Radiol. 1998;79:1499-502.

121. Reddy KM, Fiennes AG. Cholecystocolic fistula at laparoscopic cholecystectomy: primary closure and laparoscopic caecostomy. Surg Laparosc Endosc. 1998;8:400-1.

122. Hida Y, Morita T, Fujita M, Miyasaka Y, Katoh H. Laparoscopic treatment of cholecystocolonic fistula: report of a case preoperatively diagnosed by barium enema. Surg Laparosc Endosc Percutan Tech. 1999;9:217-9.

123. Kuo KK, Sheen PC, Chang SC, Chen JS, Lee KT, Cham CM. Spontaneous multiple cholecystoenteric fistulas-a case report. Kaohsiung J Med Sci. 1999;15:674-8.

124. Goenka P, Iqbal M, Manalo G, Youngberg GA, Thomas E. Colo-cholecystic fistula: an unusual complication of colonic diverticular disease. Am J Gastroenterol. 1999;94:2558-60.

125. Buła G, Niemiec A, Podwińska E. Low obturation ileus caused by gallstone incarceration in sigmoid colon. Wiad Lek. 1999;52:413-6.

126. Stagnitti F, Mongardini M, Schillaci F, Dall'Olio D, De Pascalis M, Natalini E. Spontaneous biliodigestive fistulae. The clinical considerations, surgical treatment and complications. G Chir. 2000;21:110-7.

127. Martin I, Siriwardena A. Safe laparoscopic cholecystectomy in the presence of a cholecysto-enteric fistula. Dig Surg. 2000; $17: 178-80$

128. Tocchi A, Mazzoni G, Miccini M, Puma F, Giuliani A. Acquired abnormalities of the biliary tract. Preoperative diagnosis and surgical risk in the laparoscopic era. G Chir. 2001;22:18-21.

129. Fujitani K, Hasuike Y, Tsujinaka T, Mishima H, Takeda Y, Shin $E$, et al. New technique of laparoscopic-assisted excision of a cholecystocolic fistula: report of a case. Surg Today. 2001;31:740-2.

130. Sam JW, Ghesani N, Alavi A, Rubesin SE, Birnbaum BA. The importance of morphine-augmented cholescintigraphy for the diagnosis of a subtle cholecystocolic fistula. Clin Nucl Med. 2001;26:552-4.

131. Ahn SI, Hong KC, Hur YS, Lee KY, Kim SJ, Seo JM, et al. Cholecystocolic fistula caused by blunt trauma. Injury. 2001;32:341-2

132. Moreno Ruiz FJ, del Rey Moreno A, Suescun Garcia RM, Martinez Ferriz JA, Hidalgo Garrido JM, Espadas Padial B, et al. Treatment of cholecystoduodenal fistula in the era of laparoscopy. Rev Esp Enferm Dig. 2001;93:715-20.

133. Maltz C, Zimmerman JS, Purow DB. Gallstone impaction in the colon as a result of a biliary-colonic fistula. Gastrointest Endosc. 2001;53:776.

134. Benson AJ, Reinschmidt J, Billingsley JL, Timmons JH, Parish GH. Biliary-colonic fistula diagnosed via hepatobiliary scintigraphy. Clin Nucl Med. 2001;26:150-1.

135. Tantia O, Bandyopadhyay SK, Sen B, Khanna S. Pericholecystic fistula: a study of 64 cases. Int Surg. 2002;87:90-93.

136. Dutta U, Nagi B, Kumar A, Vaiphei K, Wig JD, Singh K. Pneumobilia — clue to an unusual cause of diarrhea. Trop Gastroenterol. 2002;23:138-40.

137. De Keuleneer R, Maassarani F, Lallemand B. Mirizzi syndrome with a double biliary fistula. Acta Chir Belg. 2002;102:345-7.

138. Schoeters P, Fierens H, Colemont L, Van Moer E. A cholecystocolic fistula demonstrated by endoscopic retrograde cholangiopancreatography. Endoscopy. 2002;34:595.

139. Ramos-De la Medina A, Medina-Franco H. Biliary-colonic fistulas. Analysis of 2 cases and literature review. Rev Gastroenterol Mex. 2002;67:207-9. 
140. O'Donoghue GT, Winter D, Deasy J. Cholecystocolic fistula and large-bowel obstruction due to gallstone ileus. Arch Surg. 2003;138:1391-2.

141. Velayos Jimenez B, Gonzalo Molina MA, Carbonero Diaz P, Diaz Gutierrez F, Gracia Madrid A, Hernandez Hernandez JM. Cholecystocolic fistula demonstrated by barium enema: an uncommon cause of chronic diarrhoea. Rev Esp Enferm Dig. 2003;95:811-2.

142. Pavlidis TE, Atmatzidis KS, Papaziogas BT, Papaziogas TB. Management of gallstone ileus. J Hepatobiliary Pancreat Surg. 2003;10:299-302.

143. Stewart DJ, Lobo DN, Scholefield JH. Colonic gallstone ileus. J Am Coll Surg. 2003;196:154.

144. Kunasani R, Rastogi V, Boonswang P, Dy VC, Van der Veer L. Cholecystocolonic fistula presenting as massive lower GI hemorrhage. Gastrointest Endosc. 2003;58:142-4.

145. Arvanitidis D, Anagnostopoulos GK, Tsiakos S, Margantinis G, Kostopoulos P. Cholecystocolic fistula demonstrated by endoscopic retrograde cholangiopancreatography. Postgrad Med J. 2004;80:526.

146. Lee JH, Han HS, Min SK, Lee HK. Laparoscopic repair of various types of biliary-enteric fistula: three cases. Surg Endosc. 2004; $18: 349$.

147. Mittendorf EA, Goel A, Seaman D. Image of the month. Cholecystocolonic fistula. Arch Surg. 2004;139:907.

148. Singh AK, Gervais D, Mueller P. Cholecystocolonic fistula: serial CT imaging features. Emerg Radiol. 2004;10:301-2.

149. Sipos P, Szabo S, Ondrejka P, Hermann C, Elek G, Sugar I. Subtotal colectomy in the course of gallstone-ileus surgery. Magy Seb. 2004;57:293-6.

150. Anagnostopoulos GK, Sakorafas G, Kolettis T, Kotsifopoulos N, Kassaras G. A case of gallstone ileus with an unusual impaction site and spontaneous evacuation. J Postgrad Med. 2004;50:55-6.

151. Okada N, Hirooka Y, Itoh A, Hashimoto S, Ishikawa H, Itoh T, et al. Cholecystocolonic fistula preoperatively diagnosed by endoscopic ultrasound of the colon. J Gastroenterol Hepatol. 2005;20:1621-4.

152. Perez-Morales A, Roesch-Dietlen F, Diaz-Blanco F, MartinezFernandez S. Safety of laparoscopic cholecystectomy in complicated vesicular disease. Cir Cir. 2005;73:15-8.
153. Ishikura $H$, Sakata A, Kimura $S$, Okitsu H, Ishikawa M, Ichimori T, et al. Gallstone ileus of the colon. Surgery. 2005;138:540-2.

154. Sanchez-Garcia JL, Lopez-Cano M, Espin-Basany E, ArmengolCarrasco M. Image of the week. Cholecystocolic fistula. Med Clin (Barc). 2006;127:120.

155. Wang WK, Yeh CN, Jan YY. Successful laparoscopic management for cholecystoenteric fistula. World J Gastroenterol. 2006;12:772-5.

156. Gaillard F, Stella D, Gibson R. Cholecystocolonic fistula diagnosed with CT-intravenous cholangiography. Australas Radiol. 2006;50:484-6.

157. Sinha S, Pullan RD. Cholecystocolonic fistula: an unusual cause of large bowel obstruction. $\mathrm{Br} \mathrm{J}$ Hosp Med (Lond). 2006;67:434-5.

158. Lee JW, Kim MY, Kim YJ, Suh CH. CT of acute lower GI bleeding in chronic cholecystitis: concomitant pseudoaneurysm of cystic artery and cholecystocolonic fistula. Clin Radiol. 2006;61:634-6.

159. Gelbman A. Clinical quiz. Gallstone ileus with cholecystocolonic fistula. Emerg Radiol. 2006;12:199-200.

160. Shrestha BM, Wyman A. Cholecystocolocutaneous fistula: a case report. Hepatobiliary Pancreat Dis Int. 2006;5:462-4.

161. Deckoff SL. Gallstone ileus; a report of 12 cases. Ann Surg. 1955;142:52-65.

162. Paolucci V, Schaeff B, Schneider M, Gutt C. Tumor seeding following laparoscopy: international survey. World J Surg. 1999;23:989-97.

163. Day EA, Marks C. Gallstone ileus. Review of the literature and presentation of thirty-four new cases. Am J Surg. 1975;129:552-8.

164. Reisner RM, Cohen JR. Gallstone ileus. A review of 1,001 reported cases. Am Surg. 1994;60:441-6.

165. Gray-Turner G. A giant gallstone impacted in the colon and causing acute obstruction. Br J Surg. 1932;20:26.

166. Foss HL, Summers JD. Intestinal obstruction from gallstones. Ann Surg. 1942;115:721.

167. Rigler LG, Borman CN, Noble JF. Gallstones obstruction: pathogenesis and roentgen manifestations. JAMA. 1941;117: 1753-9.

168. Macintyre IM, Wilson RG. Laparoscopic cholecystectomy. Br J Surg. 1993;80:552-9. 